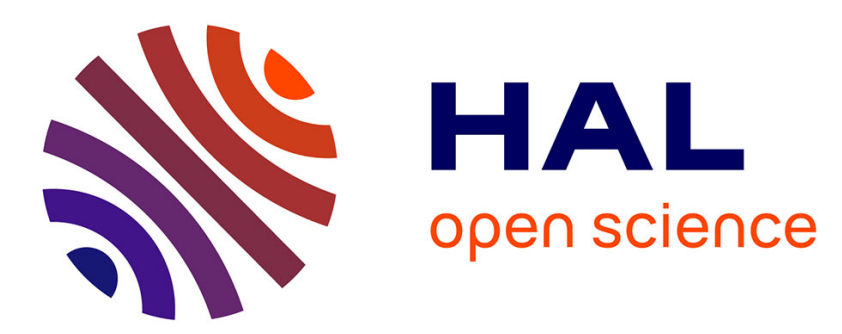

\title{
Product Lifecycle Management Approach for Integration of Engineering Design and Lifecycle Engineering
}

Diana Penciuc, Julien Le Duigou, Joanna Daaboul, Benoît Eynard, Flore Vallet

\section{- To cite this version:}

Diana Penciuc, Julien Le Duigou, Joanna Daaboul, Benoît Eynard, Flore Vallet. Product Lifecycle Management Approach for Integration of Engineering Design and Lifecycle Engineering. AI EDAM, 2016, 30 (4), pp.379-389. 10.1017/S0890060416000366 . hal-01449648

\section{HAL Id: hal-01449648 \\ https://hal.science/hal-01449648}

Submitted on 24 Feb 2020

HAL is a multi-disciplinary open access archive for the deposit and dissemination of scientific research documents, whether they are published or not. The documents may come from teaching and research institutions in France or abroad, or from public or private research centers.
L'archive ouverte pluridisciplinaire HAL, est destinée au dépôt et à la diffusion de documents scientifiques de niveau recherche, publiés ou non, émanant des établissements d'enseignement et de recherche français ou étrangers, des laboratoires publics ou privés. 


\title{
Product Lifecycle Management Approach for Integration of Engineering Design and Lifecycle Engineering
}

\author{
Diana Penciuc ${ }^{1}$, Julien Le Duigou ${ }^{2}$, Joanna Daaboul ${ }^{2}$, Flore Vallet ${ }^{123}$ and Benoît Eynard ${ }^{2}$ \\ ${ }^{1}$ Institut de Recherche Technologique SystemX, Palaiseau, France \\ ${ }^{2}$ Department of Mechanical Systems Engineering, Université de Technologie de Compiègne, UMR CNRS 7337 Roberval \\ Sorbonne Universités, Compiègne, France \\ ${ }^{3}$ Laboratoire Genie Industriel, CentraleSupélec, Université Paris-Saclay, Chatenay-Malabry, France
}

Corresponding author:

Prof. Benoît Eynard

Sorbonne Universités, Université de Technologie de Compiègne

Department of Mechanical Systems Engineering, UMR CNRS 7337 Roberval

CS 60319, 60203 Compiègne Cedex, France

Tel: +33 344237967 - Email: benoit.eynard@utc.fr 


\title{
Product Lifecycle Management Approach for Integration of Engineering Design and Lifecycle Engineering
}

\begin{abstract}
Optimized lightweight manufacturing of parts is crucial for automotive and aeronautical industries in order to stay competitive and to reduce costs and fuel consumption. Hence, aluminium becomes an unquestionable material choice regarding these challenges. Nevertheless, using only virgin aluminium is not satisfactory since its extraction requires high use of energy and effort, and its manufacturing has high environmental impact. For these reasons, the use of recycled aluminium alloys is recommended considering their properties meet the expected technical and environmental added-values. This requires complete reengineering of the classical life cycle of aluminium-based products and the collaboration practices in the global supply chain. Results from several interdependent disciplines need all to be taken into account for a global product/process optimization. Towards achieving this, a method for sustainability assessment integration into product lifecycle management and a platform for lifecycle simulation integrating environmental concerns, are proposed in this paper. The platform may be used as a decision support system in early product design phase by simulating the lifecycle of a product (from material selection to production and recycling phases) and calculating its impact on the environment.
\end{abstract}

Keywords: Engineering Design; Lifecycle Engineering; PLM; Lightweight Product; Aluminium Industry. 


\section{Introduction}

Lightweight aluminium-based products are becoming more and more important in highly-competitive industries such as automotive and aeronautical ones. These lightweight products allow cost reduction while increasing technical performance and global sustainability. As the virgin aluminium extraction is highly energy consuming, very expensive and polluting, alternative aluminium sources (alloys resulting from recycling) need to be considered. Thus, it was the aim of the European FP7 project entitled SuPLight (SuPLight, 2014) to achieve a recycling rate of $75 \%$, sufficient to replace the virgin aluminium in production. Using new alloy-based materials in production of high-end parts is very challenging, as the quality requirements they have to satisfy are very rigorous. To this end, it is necessary to thoroughly reengineer the lifecycle of aluminium-based products to enable the design of high-quality alloys from scrap, with less environmental impact. Knowledge from several disciplines has to be aggregated to prepare the lifecycle of a product from cradle to grave and from recycling back to the first lifecycle stages. Integration into design tasks of each discipline and viewpoints related to subsequent phases of product lifecycle is therefore decisive in such a context and is referred as “concurrent engineering” and "integrated design" (Sohlenius, 1992; Tichkiewitch \& Brissaud, 2003). Making the right decisions very early in design phase can significantly improve the impact on the final product cost (Ullman, 1997, Pahl et al., 2007). In the same way, sustainability-related decisions taken at this stage are of great importance as they cannot be changed later on (Luttrop \& Lagerstedt, 2006).

The World Commission on Environment Development - WCED (1987) defined the sustainable development as a "development that meets the needs of the present without compromising the ability of future generations to meet their own needs." Sustainability refers to three major concerns: environmental, economic and social (Labuschagne \& Brent, 2005) which are known as the three pillars of sustainable development (Pope et al., 2004).

Ramani et al. (2010) provide a good review of approaches for integrating sustainability in design. According to them, "the decisions have to be made based not only on structure, material, and manufacturing choices, but also on transportation, distribution, and end-of-life logistics and management". Three main areas of product development affect design choices: manufacturing 
considerations, supply-chain management and end-of-life management. Integration of the entire lifecycle of a product is necessary.

With regard to previous research, the paper proposes a method for the integration of sustainability considerations into design taking into account the entire lifecycle of a product. The method is illustrated by a platform allowing the simulation of a lifecycle, integrating multiple disciplines involved in the whole product lifecycle (design, manufacturing, recycling) and a management of environmental information.

In section 2, a literature review of main integrated design and lifecycle engineering methods is presented. Section 3 describes the objectives of the current research and introduces the proposed generic method. Section 4 shows how the method was applied to specify and implement the platform in the SuPLight project. In section 5, the case study of a front lower control arm is presented to explain the use of the platform in a real-world context. A discussion of the results is given in section 6 before concluding with outlines of future research.

\section{Related work}

The section introduces some challenges related to collaborative design activities. It also outlines a survey and review of the findings in the area of lifecycle engineering (Lofthouse, 2006; Vallet et al., 2013) and integrated design (Noël \& Roucoules, 2008; Bouikni et al., 2008; Demoly et al., 2010) with their links to PLM approaches (Jun et al., 2007; Terzi et al., 2010; Kiritsis, 2011; Le Duigou et al., 2012). These latter are seen as an opportunity for the operationalization of an integrated design method and lifecycle engineering approach. The practices for information management related to lifecycle engineering (from environmental point of view) during product lifecycle are presented for the design, manufacturing and end-of-life phases (Zhou et al. 2009; Dufrene et al., 2013; Kozemjakin da Silva et al., 2015).

Design, as defined in (Blessing \& Chakrabarti, 2009) is a complex and multifaceted phenomenon involving a tight collaboration between multi-domain product designers, a multitude of activities and 
procedures, tools and knowledge, as well as a variety of contexts which all have to converge in an organisation.

Collaboration between multi-domain product designers implies that different points of view must be taken into account to achieve the best compromise in product development (Sohlenius, 1992). A point of view is the vision and knowledge of an expert involved in a design team (Brissaud \& Tichkiewitch, 2001). An expert may be specialist of a particular lifecycle stage (e.g. manufacturing), a domain (e.g. mechanical engineer) or cross-domain (who brings expertise not linked to a life stage or a domain, but to a specific point of view on the whole life-cycle of a product, as for example the quality engineer or the environmental expert).

The environmental experts often have difficulties to share environmental information with other design experts (Lindhal, 2006; Kozemjakin da Silva et al., 2015). This could be due to the nature of the results (e.g. environmental impacts) which are difficult to link with other design parameters (material parameters, geometric parameters, etc.). It can also be due to the absence of a standard exchange format that encompasses environmental parameters, like STEP (Standard for the Exchange of Product model data) that allows information exchange from various expert tools (Chandrasegaran et al. 2013). Theret et al. (2011) argue that there is no appropriate support to exchange data during early design and between eco-design and Computer-Aided Design (CAD) systems. The last point, which results from the previous one, is the lack of interoperability between the systems used in design and those used by the environmental experts.

Rio et al., (2014) proposed a model-driven architecture based interoperability method to improve the exchange of information between eco-design and other design activities. Some software vendors worked on the integration of sustainability in traditional design tools like CAD systems (Solidworks from Dassault Systèmes) or material selection tools (CES selector from Granta Design). Russo and Rizzi , (2014) suggested another integrated eco-design method, including shape, material and production assessment integrating Life Cycle Analysis (LCA) with CAD and Finite Element Analysis. Their work focuses on a specific design stage and do not consider the environmental impact transfer 
from one stage to another. Other researchers, like Dufrene et al. (2013) proposed an integrated ecodesign methodology that improves both environmental impacts and technical characteristics. Nevertheless, these methods focus only on the Beginning of Life (BOL) and do not provide any feedback from Middle of Life (MOL) or End of Life (EOL).

One of the major difficulties the environmental experts have to cope with is the lack of information especially when they try to perform LCA (ISO14040, 2006; Curran 2006). LCA is time and resource consuming and requires a huge amount of heterogeneous data from all over the extended enterprise. Some of them could be extracted from the digital mock-up. The needs of integration between CAD, PLM and LCA were already underlined in (Mathieux et al., 2007). However, this approach considers only the BOL stage, and do not encompass the MOL or EOL stages, although this information is essential in most of the product lifecycle engineering. To make a clear and useful analysis of environmental impacts, this information must be specialized and accurate (Pavković et al., 2013).

PLM is a business strategy allowing all lifecycle stakeholders to manage and integrate product information at each phase of its lifecycle. It enables cross-exchange between the manufacturing information, the MOL information (modes of use, usages environment, maintenance tasks and spare parts, etc.) as well as the EOL information (recycling rate, reverse logistic routes, etc.) (Främling et al., 2013). Nevertheless, in the existing PLM systems (like Enovia from Dassault Systèmes, Teamcenter from Siemens PLM or Windchill from PTC) implementing the PLM approach, the integration between the different information collected and lifecycle processes is still incomplete and there exists a need for stronger interoperability between information systems (Raffaeli et al., 2013).

To summarize, sustainability is an important requirement for industry and information management an important challenge for the current century. Methods and systems allowing the integration of sustainability during product development exist, but they are not mature enough as they target only a part of the product lifecycle and more particularly, only the BOL phase. The results provided by this kind of tools cannot provide a realistic estimation of the current product development impact as regard to sustainability goals. They use generic data about MOL and EOL and do not integrate the 
environmental impact in their design decisions. A PLM approach is mandatory to provide connexion to specific tools supporting sustainability (e.g. eco-design, reverse logistics etc.) with classical design tools (CAX). This will allow to get more precise data about the material, the geometry, the process, the use, the reverse logistic routes, etc. to enable better estimation of the environmental impact and to make better design choices.

\section{Platform specification for PLM approach for integration of engineering design and lifecycle engineering}

The proposed method to specify a PLM system for integrated design and lifecycle engineering is shown in Figure 1.

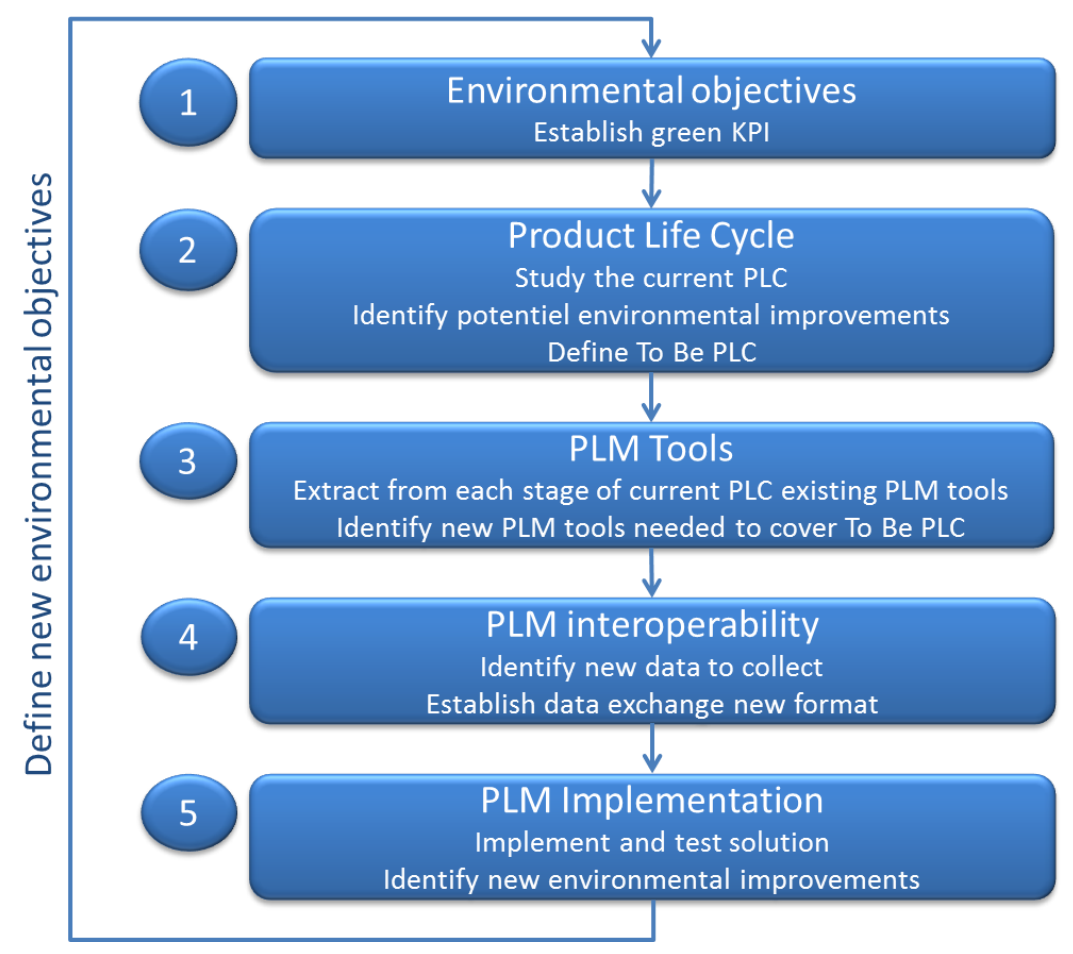

Figure 1 : Method for environmentally conscious integrated design.

This method is composed of five steps:

1. Environmental Objectives: Environmental objectives should be defined according to international or local legislation, standards, etc. which are relevant to the field of activity 
considered. Success in achievement of initial goals can be measured by key-performance indicators (Fitz-Gibbon, 1990).

2. Product Life Cycle: Knowing the current product lifecycle is strategic for the identification of potential improvements and for the future specification of the PLM system. This step allows to clarify the activities involved in product development and to detect the ones that govern the environmental impact of a product.

3. PLM Systems and Tools: The purpose of this step is to make an inventory of the existing systems and identify new features/tools needed (Assouroko et al., 2014). Traditional tools in design, manufacturing and maintenance must be combined with tools supporting sustainability assessment: design for environment, eco-design, environmentally conscious manufacturing, and end-of-life management (reverse logistics) tools.

4. PLM interoperability: Changes in the product lifecycle, like integrating new practices or new tools, induce changes at the information management level (data flows between the stakeholder/tools will change). Therefore, information exchange has to be redefined taking into account all the tools in the new lifecycle and their coordination (information flow sequence).

5. PLM Implementation: The last step of the method is to define appropriate architecture and technology implementation to support the integration of the existing systems and new tools in the context of the new lifecycle. Tools may be owned by distributed partners and each of them handles data using their own format for information representation (Belkadi et al. 2010). Requirements for the platform have to take into account: 1- the need of easy reconfiguration and its use in context of extended enterprise (Ross et al., 2006); 2- an easy integration of existing systems and tools as well as new tools needed to improve current practices.

This method enables to connect most of the design tools and to integrate environmental impact evaluation into the design process. Data generated by each tool will be precise and accurate. Then they can be used to assess more precisely the environmental impact. This impact will be also directly linked 
with the tools to be able to provide accurate decision support to designers. The 5 steps of the method consist of several tasks which will be described in details in the next section.

\subsection{Step 1: Environmental objectives}

As stated before, the final goal of the SuPLight project is to achieve a high rate of re-use of recycled aluminium (namely 75\%), with respect to environmental regulations, quality, customer expectations, etc. In this project, the relevant indicators are related to productivity (manufacturing time), quality (aluminium alloy properties: material, chemical, mass, etc.), consumption of energy in production, and use of chemicals/emissions.

22 key performance indicators were defined to determine the Aluminium Industry's progress along the sustainable development path by "The Global Aluminium Sustainable Development Initiative" (2002). Among them, the below performance indicators were identified by the project partners as relevant to the SuPLight aims (see Table 1). These indicators were then translated into operational indicators measuring the environmental, technical and economic performances.

\begin{tabular}{|l|l|l|}
\hline \multirow{2}{*}{$\begin{array}{l}\text { Environmental } \\
\text { indicators }\end{array}$} & Initial performance indicators selected & $\begin{array}{l}\text { Operational performance } \\
\text { indicators }\end{array}$ \\
\cline { 2 - 4 } & Fresh water consumption for production & Water withdrawal \\
\cline { 2 - 4 } & $\begin{array}{l}\text { Use of energy (renewable/non-renewable) } \\
\text { in production }\end{array}$ & Non-renewable energy \\
\hline \multirow{2}{*}{ Economic } & $\begin{array}{l}\text { Amount of recycled aluminium used in } \\
\text { indicators }\end{array}$ & Recycling rate \\
\cline { 2 - 4 } & \begin{tabular}{l} 
EOL indicators \\
\cline { 2 - 4 }
\end{tabular} & Reverse logistics network cost \\
\hline
\end{tabular}




\begin{tabular}{|l|l|l|}
\hline Quality indicators & Lightweight component mass & Mass \\
\hline
\end{tabular}

Table 1: Selection of the relevant environmental indicators

\subsection{Step 2: Product Life Cycle}

In the following, the manufacturing phase of aluminium parts lifecycle is detailed to illustrate this step. The lifecycle was reproduced based on two industrial cases in SuPLight project and the Aluminium recycling process described in the 2009 Global Aluminium Recycling report developed by the International Aluminium Institute (GARC, 2009).

Figure 2 explains the "classic manufacturing phase": the virgin aluminium is extracted and transformed in billets by "Casting", then sent to "Forming" where they are transformed into a usable industrial form which gives the material the properties of lightness, strength and durability. The resulting initial "Product shape" is then processed into a machined part during the "Machining and Finishing" process before obtaining the finished assembled part during "Assembly". The tools used in each phase are shown with dotted line.

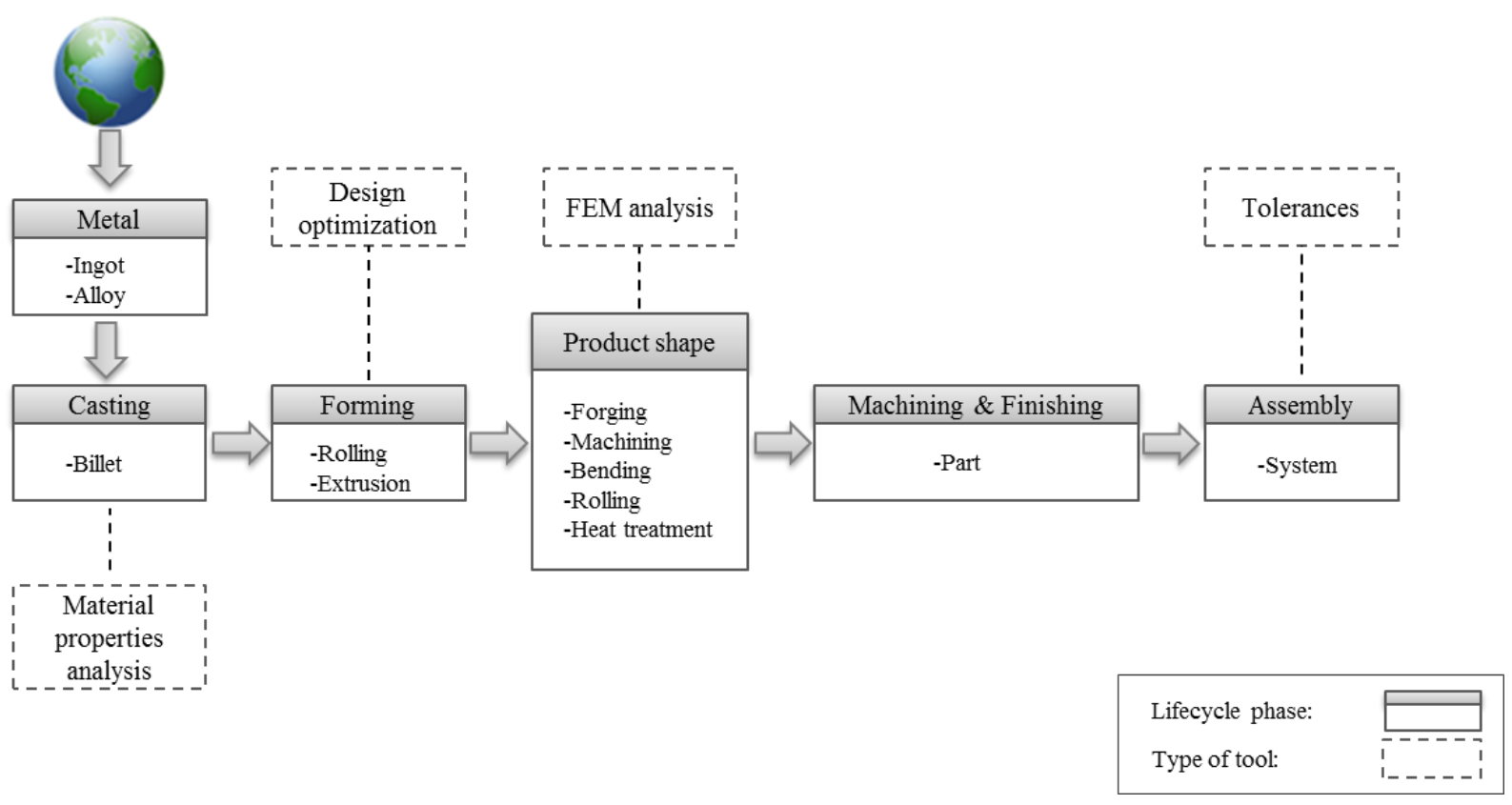

Figure 2: Excerpt of product lifecycle modelling (manufacturing phase) 
An aluminium recycling loop is already established for aluminium used in lower-end products (the scrap is either directly sent to a recycling company or, if it is not pure enough, to a refiner for further purification). On the contrary, there exists no established recycling loop for wrought aluminium used in high-end products. In the latter case, the quality requirements are more stringent. Therefore, the recycling process has to be completed, as to ensure an optimal reuse of aluminium scrap in high-end products without neglecting its impact on the environment. As new materials are used in production, the risks associated to them need to be managed (for e.g. risks related to the material properties, geometry etc.). Complex multi-disciplinary tests are useful to try to identify potential failures and to reduce risks. Variation sources can be in material properties or manufacturing parameters such as stamping pressure, thermal conduction, temperature, friction etc.

\subsection{Step 3: PLM Systems and Tools}

An inventory of the existing tools used by the industrial partners allowed identifying the lack of Computer-Aided X (CAx) systems integrating the sustainability management issues at BOL, MOL and EOL phases. Therefore, integrating eco-design (Andriankaja et al., 2015) and reverse logistics (Daaboul et al., 2014) tools to the current lifecycle was highly recommended. In the SuPLight project both "process improvement and optimization" and new "green processes" were considered as alternatives for the improvement of the current production process. Based on these observations, a number of six components called plugins were identified as mandatory to achieve the established goals.

The plugins are dedicated software providing optimisation in specific phases of the product lifecycle. A plugin may be an existing tool (or combination of several existing tools) as well as a new tool (developed ad-hoc to meet the purpose of the project). It is to be noted that two of the green tools used in the project are the eco-design and reverse logistics tools. The plugins are described below.

The MATerial plugin (MAT) determines the material and mechanical properties of the alloys. These later are further used by the Design optimisation and Finite Element Method (FEM) plugins to calculate the behaviour of the alloy parts. 
The Design Optimisation (DO) plugin performs an analysis in order to find alternative topologies for the part that fulfil the stiffness, weight criteria, eigenvalues and centre of gravity. The output of this plugin includes the CAD files used as an input to the Finite Element Method plugin.

The Finite Element Method plugin (FEM) assesses the forging process for the part defined by the Design Optimisation. The output of this plugin includes the CAD files for the Tolerance plugin.

The Tolerance plugin (TO) uses a meta-model for tolerance analysis and geometric variation simulation to provide rapid results based on a more extensive computation module.

The Reverse Logistics plugin (RL) aids at designing the reverse logistics network including location/allocation of facilities, partner (supplier) selection and the design of the transportation network, based on the characteristics of the components involved (Daaboul et al., 2014).

The Eco-design plugin (EcoD) computes environmental impact based on the characteristics of the product and the transportation network used (Andriankaja et al., 2015). The Eco-Design plugin performs a simplified lifecycle assessment of the design properties and environmental impact based on the input decisions made in other plugins.

\subsection{Step 4: PLM interoperability}

A common agreement on the terms used by each partner as well as a common representation of the information exchanged between heterogeneous tools (the plugins) was defined as a dictionary. To be clear, the dictionary specified a single term for distinct terminologies used by the partners/tools and an associated unique notation for information exchange (e.g. the notation "machined_product_mass" indicates the mass of the product after the "machining" process, see Figure 3), a unit of measure (e.g. $\mathrm{kg}$ ) and a data type (e.g. double).

Once the dictionary established, the second step consisted in the definition of the information exchange between the plugins. In Figure 3, the information flow is indicated by the arrows: the ecodesign plugin collects information from several other plugins and sends the results (the environmental indicators) back to the reverse logistics plugin. The configuration of plugins used and their sequence 
may change if one or more plugins are added/ deleted from the simulation loop. As compared to Figure 2 outlining the initial product lifecycle, it can be noticed that new information was integrated from two new plugins (eco-design and reverse logistics) in order to consider the environmental impact.

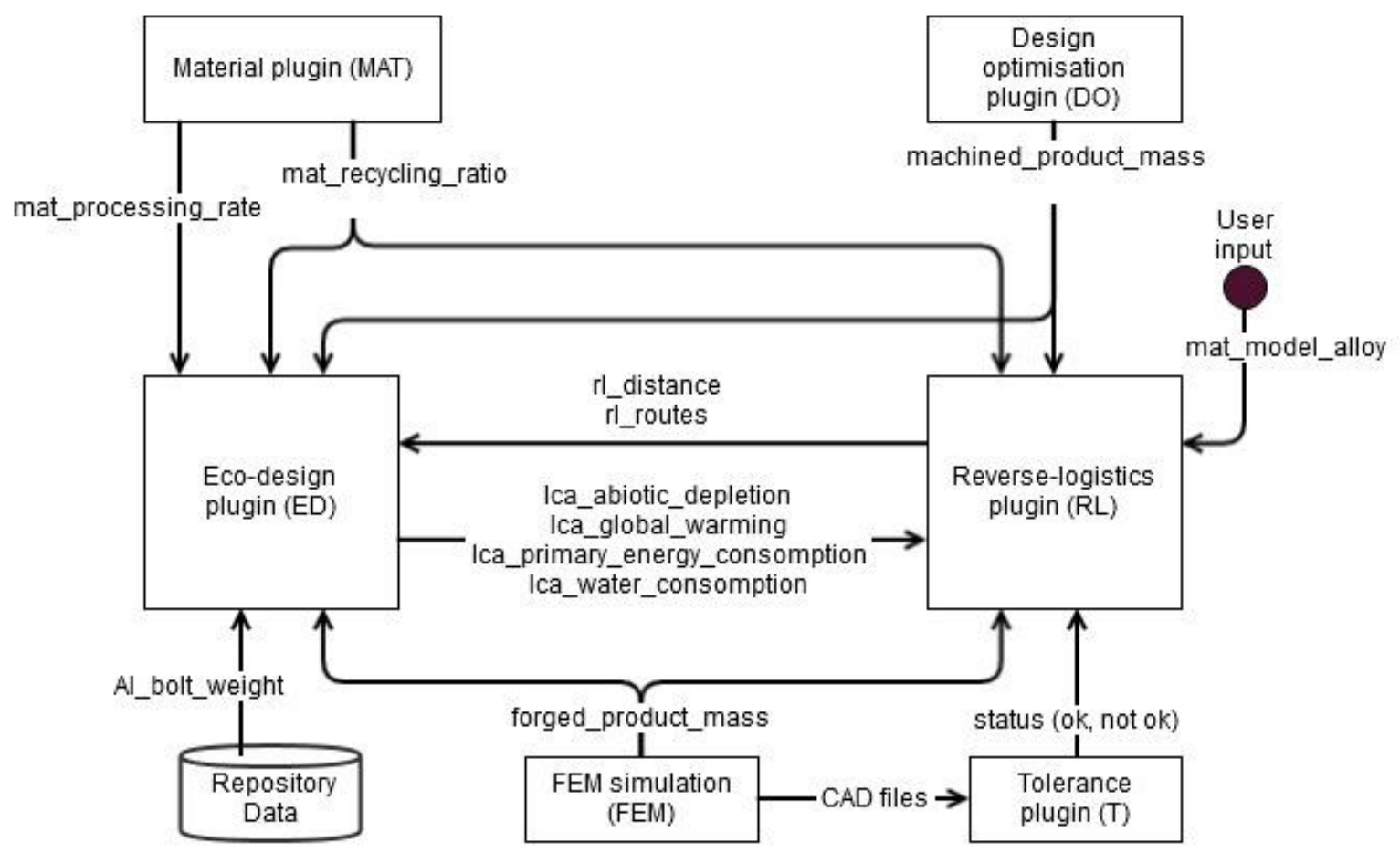

Figure 3: Information exchange between the plugins during the product lifecycle

\subsection{Step 5: PLM Implementation}

According to the previously established requirements, the architecture of the platform needs to be flexible and extendable, and also has to support the integration of distributed systems and tools. According to (Hachani et al., 2013), Service Oriented Architecture (SOA) is therefore considered as a good candidate enabling capabilities like agility, business alignment, consolidation of redundant applications, better organization and integration of coexisting systems, tools, etc.

A common SuPLight format was specified (the SuPLight namespace) to set a standardized format for enabling information exchange and management based on the proposed dictionary. All "Simple Object 
Access Protocol" messages sent between the communicating modules follow the rules settled by the SuPLight format. The plugins have their own interfaces and some of them may also be used as independent software and, therefore, they have two functioning modes (independent and integrated mode). In the integrated mode, they run as part of the closed-loop and they are provided with a common interface, accessible online within the SuPLight simulation platform (https://collab.suplight.eu/sim/). This interface is automatically generated based on a plugin declaration. The plugin declaration consists in editing overall properties (name, namespace prefix, description, documentation etc.) as well as the input/output of the plugin. Web services were defined and implemented for each plugin, according to their legacy format. Servlets handle web service calls from the SuPLight platform and translates them into legacy format. The services provided by each plugin were published in a registry implemented as $\mathrm{TAS}^{3}$ Discovery Service (www.tas3.eu). The module for information management handles the execution of the plugins in the optimization loop. At this level, the plugin sequence and the mapping between the input and output of each plugin are managed. In the front-end, the execution sequence may be set from the Graphic User Interface and the execution of the simulation sequence may be visualized step-by-step (results from each plugin) or atonce (final result).

\section{Case study: front lower control arm}

In this section a case study is introduced in order to illustrate the use of the SuPLight platform for lifecycle simulation. The considered part is a front lower control arm, which is a part of the suspension system of a car (see Figure 4). The chosen control arm is manufactured from AA6082 which is a high strength wrought aluminium alloy. The baseline process for the manufacturing of the control arm is:

- Manufacturing of AA6082 ingots from virgin aluminium and treated production scrap

- Extrusion of ingots to produce the AA6082 rods;

- Cutting rods into pieces and annealing to soften the billet and make it easier to forge;

- Rods forging; 
- Aging rods (which increases the strength of the aluminium alloy);

- Machining and assembly of the control arm.

The production (or pre-consumer) scrap is treated to remove the fluids and dirt and is then reused in the manufacturing of the AA6082 ingot.

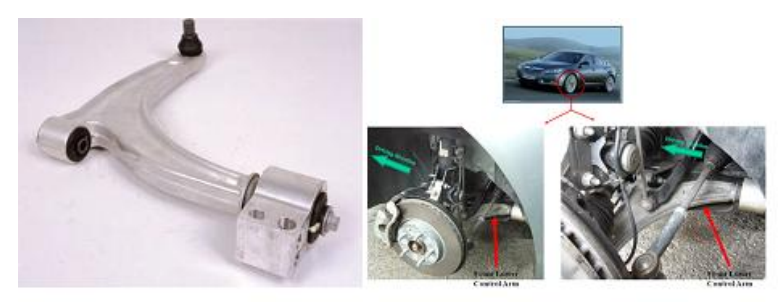

Figure 4: The front lower control arm

Several scenarios were proposed, with the purpose of specifying the optimal aluminium alloy properties to be used for the control-arm to achieve the best global performance (in terms of resistance, rate of recycled aluminium or environmental impacts). The scenarios were then compared to each other against the list of indicators considered relevant with regard to cost, quality and environmental concerns. Three Al alloys were identified as eligible, with respect to the quality needed for high-end products manufacturing. The scenarios presented in this paper concern the "Alloy 1" and "Alloy 2" (see Table 2 for the alloy composition). To achieve sustainability in manufacturing, an optimized production process was proposed as an alternative to the baseline. This optimized process consists in increasing the use of recycled material, while considering all suitable scrap sources (end-of-life vehicles, building demolition and end of life packaging).

\begin{tabular}{|l|l|l|l|l|l|l|}
\hline & SI & $\mathrm{Mg}$ & $\mathrm{Fe}$ & $\mathrm{Cu}$ & $\mathrm{Mn}$ & $\mathrm{Zn}$ \\
\hline Primary aluminium & 0.05 & 0.01 & 0.1 & 0.01 & 0.01 & 0.03 \\
\hline Alloy 1 & 0.92 & 0.75 & 0.16 & 0.01 & 0.4 & 1.1 \\
\hline Alloy 2 & 1.02 & 0.75 & 0.25 & 0.91 & 0.54 & 0.2 \\
\hline
\end{tabular}

Table 2 : Alloy composition

Figure 5 highlights the communication between the plugins in the simulation loop. For simplicity, only the interaction and detailed information exchanged during the last steps of the simulation loop are 
discussed, namely the exchanges between the Reverse Logistic (RL) and Eco-Design (ED) plugins. These plugins calculate significant indicators in the simulation loop (the environmental impact indicators and the reverse logistics indicators). A summary of the indicators is presented in Table 3. The inputs to the Reverse Logistic plugin are: the alloy type (input data), the mass (calculated by the Design Optimisation (DO plugin) and the recycling ratio expected at the end (sent by the MATerial plugin). The Reverse Logistic plugin determines all possible Reverse Logistic networks and sends the Reverse Logistic network characteristics (total distance of the network, and the routes: flow transported, transportation means etc.) to the Eco-Design plugin, which then computes the environmental indicators and sends them back to the Reverse Logistic plugin.

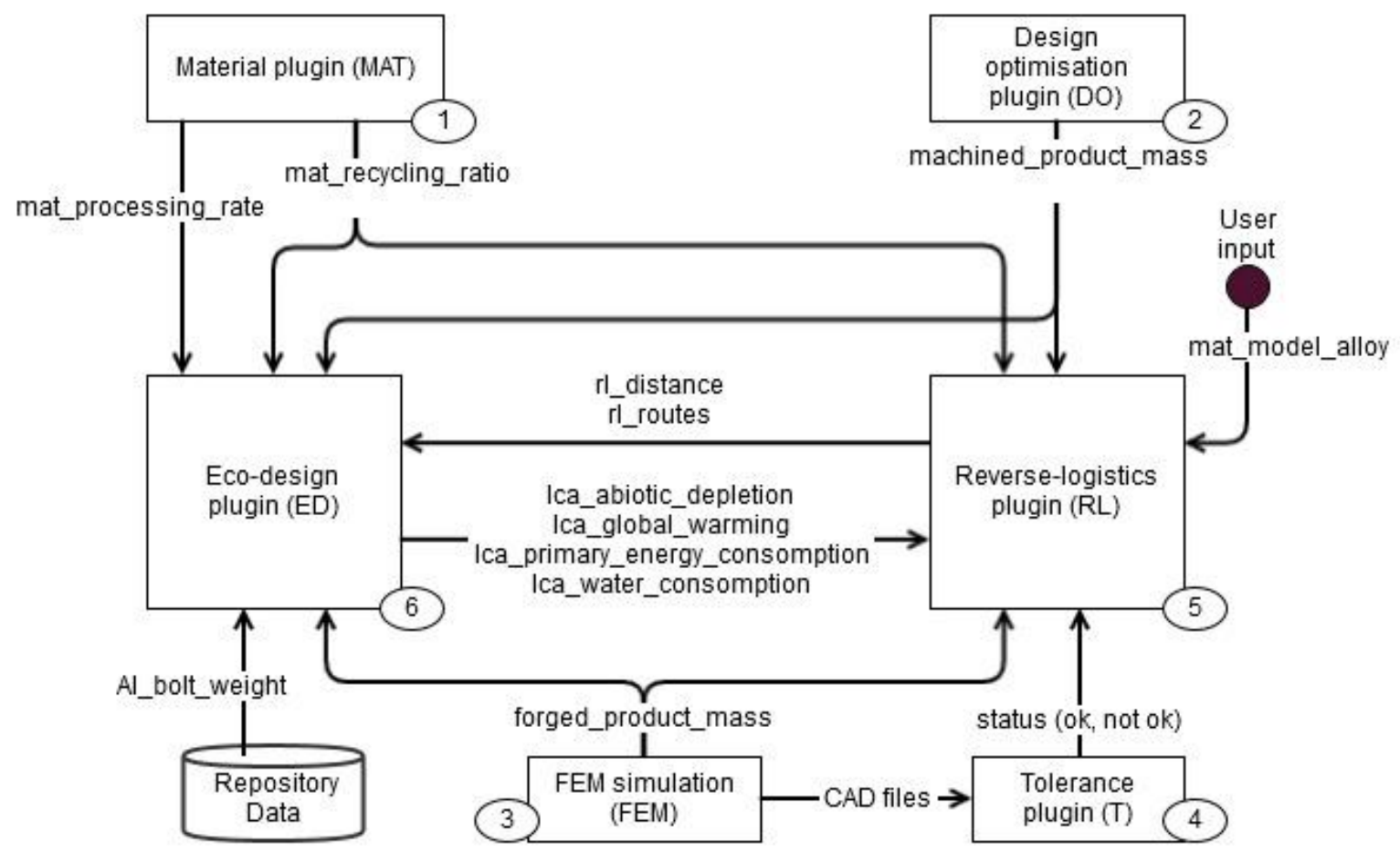

Figure 5: Information exchange and management between the plugins in the simulation platform

\begin{tabular}{|c|c|c|c|}
\hline Indicators & Unit & Plugin displaying indicators & Plugin calculating indicators \\
\hline Global warming & Kg CO2-eq & LCA/Eco-design, RL & LCA/Eco-design \\
\hline
\end{tabular}




\begin{tabular}{|l|c|c|c|}
\hline Potential & & & \\
\hline Water withdrawal & $\mathrm{m} 3$ & LCA/Eco-design, RL & LCA/Eco-design \\
\hline Non-renewable & MJ primary & LCA/Eco-design, RL & LCA/Eco-design \\
energy & & & $\mathrm{RL}$ \\
\hline RL network cost & euros & $\mathrm{RL}$ & $\mathrm{RL}$ \\
\hline Recycling rate & $\%$ & $\mathrm{RL}$ & \\
\hline
\end{tabular}

Table 3 : Indicators considered for the estimation of the environmental and economic performance of the

scenarios

As shown in Table 4 and Table 5, five scenarios were proposed, considering: 1) a variation of the recycling rate and a constant mass as well as 2) a mass variation and a constant recycling rate.

\begin{tabular}{|c|c|c|c|}
\hline Scenario & Alloy type & Mass (kg) & Recycling ratio (\%) \\
\hline Scenario 1 (baseline) & Alloy 1 & 0.002649 & 0 \\
\hline Scenario 2 & Alloy 1 & 0.002649 & 40 \\
\hline Scenario 3 & Alloy 1 & 0.002649 & 60 \\
\hline
\end{tabular}

Table 4 : Scenarios for simulation: variation in recycling rate and material used, constant mass

\begin{tabular}{|c|c|c|c|}
\hline Scenario & Alloy type & Mass (kg) & Recycling ratio (\%) \\
\hline Scenario 4 & Alloy 2 & 0.002693 & 75 \\
\hline Scenario 5 & Alloy 2 & 0.002259 & 75 \\
\hline
\end{tabular}

Table 5 : Scenarios for simulation: constant recycling rate, mass variation

Scenario 1 is the baseline. The mass is the initial one, with an $\mathrm{Al}$ alloy that do not contain any recycled Al. The Functional Unit considered for this study is expressed as follows: "2 control arm bodies (left and right sides) equipping a GM Opel Insignia Diesel version over an average life time mileage of 200 $000 \mathrm{~km} "$ (Andriankaja et al., 2015). For the baseline, the control arm body is recycled at its EOL, but no Reverse Logistics (RL) scenario is specified. 
In scenarios 2 and 3 , the percentage of recycled $\mathrm{Al}$ is increased. This impacts the material characteristics, the process, the reverse logistic routes flow and cost. The plugin sequence used in the simulation platform is: $\mathrm{MA} \rightarrow \mathrm{FEM} \rightarrow \mathrm{T} \rightarrow \mathrm{RL} \rightarrow \mathrm{ED} \rightarrow \mathrm{RL}$.

In scenarios 4 and 5, the recycling rate is maintained to the targeted value (75\%), and the topology optimisation plugin allows a mass reduction in scenario 5. The plugin sequence used in the simulation platform is: $\mathrm{MA} \rightarrow \mathrm{DO} \rightarrow \mathrm{FEM} \rightarrow \mathrm{T} \rightarrow \mathrm{RL} \rightarrow \mathrm{ED} \rightarrow \mathrm{RL}$.

The results obtained when comparing the alternative scenarios (Scenario 2, 3 and 5) against the baseline (recycling ratio=0\%) are shown in Figure 6. The improvements, as regard to the total lifecycle impact and the total cost of the Reverse Logistic network, are defined in percentage. The environmental impact was calculated by the LCA/Eco-design plugin for each main lifecycle stage: BOL, MOL, and EOL. Only the optimal Reverse Logistic network was considered for each scenario, although several alternative Reverse Logistic networks are possible in each case. The environmental impact improvement obtained in Scenario 5 is considerable (>10\%), which is not the case for Scenarios 2 and 3 where a lower recycling rate is used. It can be noticed that the cost of the Reverse Logistic network may be maintained relatively constant (Scenario 2 and Scenario 5) while reducing the component mass and increasing the recycling ratio.

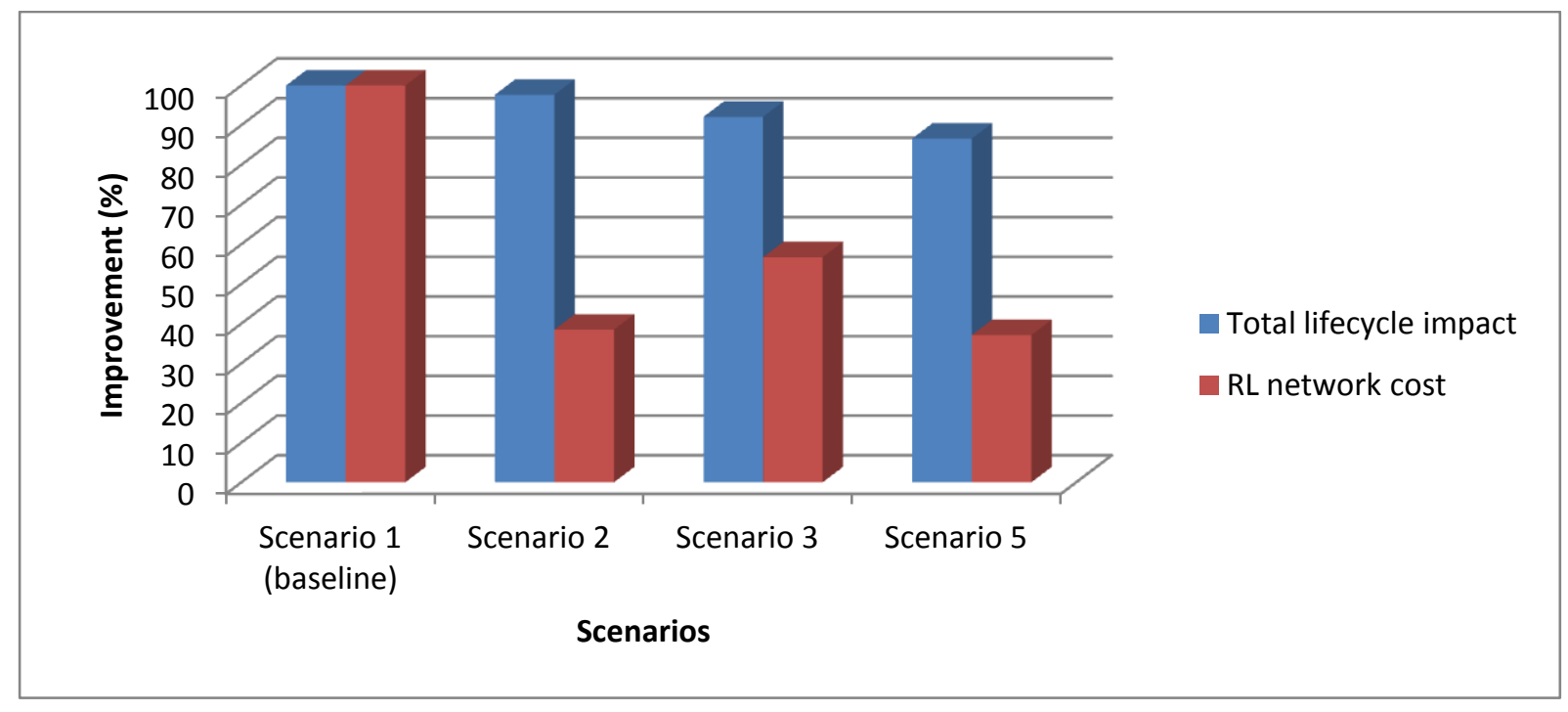

Figure 6: Histogram showing a comparison between several scenarios for the control arm production 


\section{Discussion of the obtained results}

The obtained results (see Figure 6) show that the overall lifecycle impact decreases as the recycling rate increases. Nevertheless, the economic performance of the reverse logistics network is altered when increasing the recycling rate while keeping the component mass constant. The best performance is obtained when increasing the recycling rate and reducing the component mass (Scenario 5), in other words, when a trade-off is made between the technical, environmental and economic indicators. In each case, results show that the integrated approach leads to an improved global performance compared to the current product lifecycle (Scenario 1). According to Wijngaards et al. (2003), the integrated approach also shows that the decisions made across several disciplines conduct to the best compromise when results are shared among numerous and distributed expertise (as illustrated before for the reverse logistics and eco-design).When considering only the results issued from the eco-design plugin, one may conclude that the best scenario from environmental point of view is to increase the recycling rate, whereas considering both eco-design and reverse logistics emphasizes that the optimal performances may be reached when balancing the recycling rate augmentation and the mass reduction of part.

Regarding the proposed model for information management, it can be noticed that there is a strong dependency between the component mass, the recycling ratio and the used alloy. The component mass reduction may be more or less optimized depending on the used alloy. The performance of the Reverse Logistic is directly influenced by this information and the capacity to collect and transport the necessary flows from the partners in the Reverse Logistic network. In addition, the lifecycle performance computations carried out by the eco-design plugin (BOL, MOL, EOL) is achieved by collecting information from all the other plugins in the optimisation loop: aluminium bolt weight (repository data), reverse logistics routes and distance (Reverse Logistic plugin), the material processing rate (MATerial plugin) and the product mass (machined and forged mass from Design Optimisation and Finite Element Method plugins).

According to these results it can be underlined the huge importance of a proactive and consistent information management between disciplines and expertise involved in the lightweight part 
development and manufacturing. The use of integrated design and lifecycle engineering methods is of a huge benefit. The implementation of an interoperable PLM platform with associated tools is also a key success factor.

\section{Conclusion and future work}

This paper presented a method and implementation of an interoperable PLM platform as support for integrated design and lifecycle engineering. As shown in the research survey, an integrated and collaborative design initiative has to consider the synergy between several fields: lifecycle engineering, product design and related disciplines such as manufacturing, supply-chain management and end-of-life management. Previous research work focused on local initiatives for improving sustainability assessment during product design, particularly on BOL but often neglecting the EOL phase, which do not allow to integrate all the useful information, nor to maintain sustainability across the whole product lifecycle.

To cope with this lack in the previous work, the present research work addressed the sustainability from technical, environmental and economic point of view and the integration between design and end-of-life management. The steps of the proposed general approach were illustrated on the case of the European SuPLight project aiming to provide solutions for lightweight high-end products. Several scenarios were described for the simulation of information exchange and management in the PLM platform based on a front-lower control arm case study. Results have shown that, as compared to the classical approach, the integrated approach brings significant improvements provided that a balance is maintained between the economic, technical and environmental priorities.

In this study, the possibility to use a novel process was tested by excluding the extrusion phase and forging directly from cast ingots (because of the complexity of the extrusion process and its sensitivity for chemical composition of the alloy). But the results were not successful. The $\mathrm{Al}$ alloy has a lower formability especially with a higher recycling rate due to $\mathrm{Al}$ alloy chemical composition. Other process routes can be explored as solid state recycling routes (hot extrusion, screw extrusion or spark plasma sintering) that reduce environmental impacts with a factor of 2 to 4 (Duflou et al., 2015). 
Finally additive manufacturing is gaining widespread attention for its ability to produce high quality structural metallic components with significant cost reduction of and lead-time improvement (Atzeni, and Salmi, 2012). It has endogenous characteristics for sustainable production of Al structural parts (Diegel et al., 2010) and must be studied in future work.

The second future work is related to the fact that this study was done in a lightweight aluminium context. The proposed method aims to improve recycling rate and decrease weight of structural parts integrating engineering design and lifecycle engineering. It can easily be applied to metallic parts (steel for example) with the same goals. For other materials (e.g. plastic or composite), the method can be applied even if the plugins will be different (the material plugin, the topology plugin, the process plugin will be different but will exchange the same information). More industrial cases with diversified materials should be investigated to confirm the extensibility of the proposed method.

\section{Acknowledgements}

The authors would like to acknowledge the European Commission for it financial support through the SuPLight FP7 project (grant agreement $n^{\circ}$ 263302). We also wish to express our gratitude and appreciation to all the project partners for their contribution during the development of various ideas and concepts presented in this paper.

\section{References}

Andriankaja H., Vallet F., Le Duigou J., \& Eynard B. (2015), A method to ecodesign structural parts in the transport sector based on Product Life cycle Management, Journal of Cleaner Production, 94, $165-176$

Assouroko I., Ducellier G., Eynard B., \& Boutinaud Ph. (2014), Knowledge management and reuse in collaborative product development - A semantic relationship management based approach, International Journal of Product Lifecycle Management, 7(1), 54-74 
Atzeni, E., \& Salmi, A., (2012), Economics of additive manufacturing for end-usable metal parts, International Journal of Advanced Manufacturing Technology, 62(9-12), 1147-1155

Belkadi F., Troussier N., Eynard B., \& Bonjour E. (2010), Collaboration based on Product Lifecycles Interoperability for Extended Enterprise, International Journal on Interactive Design and Manufacturing, 4(3), $169-179$

Blessing L.T.M., \& Chakrabarti A. (2009), DRM - A Design Research Methodology, London: Springer-Verlag.

Bouikni N., Rivest L., \& Desrochers A. (2008), A Multiple Views Management System for Concurrent Engineering and PLM, Concurrent Engineering: Research and Applications, 16(1), 61-72

Brissaud D., \& Tichkiewitch S. (2001), Product Models for Life Cycle. CIRP Annals - Manufacturing Technology, 50(1), 105-108.

Chandrasegaran S.K., Ramani K., Sriram R.D., Horváth I., Bernard A., Harik R.F., et al., (2013) The evolution, challenges, and future of knowledge representation in product design systems, ComputerAided Design, 45(2), 204-228

Curran M.A. (2006). Life Cycle Assessment: Principles and Practice EPA/600/R-06/060.

Daaboul J., Le Duigou J., Penciuc D., \& Eynard B. (2014) Reverse logistics network design: a holistic life cycle approach, Journal of Remanufacturing, 4(7).

O. Diegel, O., Singamneni, S., Reay, S., Withell, A., 2010, Tools for sustainable product design: additive manufacturing, Journal of Sustainable Development, 3(3), 68-75

Demoly F., Monticolo D., Eynard B., Rivest L., \& Gomes S., (2010) Multiple viewpoint modelling framework enabling integrated product-process design, International Journal on Interactive Design and Manufacturing, 4(4), 269-280

Duflou, J.R., Tekkaya, A.E., Haase, M., Welo, T., Vanmeensel, K., Kellens, K., Dewulf, W., \& Paraskevas, D., (2015) Environmental assessment of solid state recycling routes for aluminium alloys: 
Can solid state processes significantly reduce the environmental impact of aluminium recycling?, CIRP Annals - Manufacturing Technology, 64(1), 37-40

Dufrene M., Zwolinski P. \& D. Brissaud (2013), An engineering platform to support a practical integrated eco-design methodology, CIRP Annals - Manufacturing Technology, 62, 131-134.

Fitz-Gibbon C.T. (1990), Performance indicators, BERA Dialogues (2), Clevedon: Multilingual Matters.

Främling K., Holmström J., Loukkola J., Nyman J., \& Kaustell A. (2013), Sustainable PLM through Intelligent Products, Engineering Applications of Artificial Intelligence, 26(2), 789-799.

Global Aluminium Recycling (2009): A cornerstone of sustainable development, International Aluminium Institute - http://www.world-aluminium.org/media/filer_public/2013/01/15/f10000181.pdf (accessed June 2015).

Hachani, S., Gzara, L., \& Verjus, H., (2013). A service-oriented approach for flexible process support within enterprises: application on PLM systems. Enterprise Information Systems, 7(1), 79-99.

ISO14040 (2006), Environmental management - life cycle assessment-principles and framework, Geneva: $\quad$ International Standard $\quad$ Organisation http://www.iso.org/iso/catalogue_detail?csnumber=37456 (accessed June 2015).

Jun H.B., Kiritsis D. \& Xirouchakis P. (2007), Research issues on closed-loop PLM, Computers in Industry, 58(8-9), 855-868.

Kiritsis D. (2011), Closed-loop PLM for intelligent products in the era of the Internet of things, Computer-Aided Design, 43(5), 479-501.

Kozemjakin da Silva M., Remy S., \& Reyes T. (2015), On providing design process information to the environmental expert, Research in Engineering Design, 26(4), 327-336 
Labuschagne C., \& Brent A.C. (2005), Sustainable project life cycle management: the need to integrate life cycles in the manufacturing sector. International Journal of Project Management, 23(2), $159-168$.

Le Duigou, J., Bernard, A., Perry, N. \& Delplace, J.C., (2012). Generic PLM system for SMEs: application to an equipment manufacturer. International Journal Product Lifecycle Management, 6(1), $51-64$.

Lindhal M. (2006). Engineering designers' experience of design for environment methods and toolsRequirement definitions from an interview study. Journal of Cleaner Production, 14, 487-496

Lofthouse, V. (2006). Ecodesign tools for designers: defining the requirements. Journal of Cleaner Production, 14, 1386-1395

Luttrop C. \& Lagerstedt J. (2006). Ecodesign and the Ten Golden Rules: generic advise for merging environmental aspects into product development. Journal of Cleaner Production, 14, 1396-1408

Mathieux F., Brissaud D., Roucoules L. \& Lescuyer L. (2007), Connecting CAD and PLM systems with ecodesign software: current experiences and futures opportunities, Proc. Int. Conf. Engineering Design - ICED’07, Paris: The Design Society.

Noël F. \& Roucoules L., (2008) The PPO design model with respect to digital enterprise technologies among product life cycle, International Journal of Computer Integrated Manufacturing, 21(2), 139145

Pahl G., Beitz W, Feldhusen J. \& Grote K.H. (2007). Engineering Design - A Systematic Approach, 3rd Edition. London: Springer-Verlag.

Pavković N., Štorga M., Bojčetić N., \& Marjanović D. (2013). Facilitating design communication throught engineering information traceability. Artificial Intelligence for Engineering Design, Analysis and Manufacturing, 27(2), 105-119 
Pope J., Annandale D. \& Morrison-Saunders A. (2004), Conceptualising sustainability assessment. Environmental Impact Assessment Review, 24(6), 595-616.

Raffaeli R., Mengoni M. \& Germani M. (2013), Improving the link between computer-assisted design and configuration tools for the design of mechanical products, Artificial Intelligence for Engineering Design, Analysis and Manufacturing, 27(1), 51-64

Ramani K., Ramanujan D., Bernstein W.Z., Zhao F., Sutherland J., Handwerker C., Choi J.K., Kim H.\& Thurston D. (2010). Integrated Sustainable Lifecycle Design: A Review. Journal of Mechanical Design, 132(9), 1-15.

Rio M., Reyes T. \& Roucoules L. (2014), FESTivE: An information system method to improve product designers and environmental experts information exchanges, Journal of Cleaner Production, $83,329-340$.

Ross J.W., Weill P., \& Robertson D.C. (2006), Enterprise Architecture as Strategy: Creating a Foundation for Business Execution. Boston: Harvard Business School Press.

Russo D. \& Rizzi C. (2014), Structural optimization strategies to design green products, Computers in Industry, 65(3), 470-479.

Sohlenius G. (1992), Concurrent Engineering. CIRP Annals - Manufacturing Technology, 41(2), 645655.

SuPLight (2014), Sustainable and efficient Production of Light weight solutions, FP7-FoF-NMP-2010, http://www.suplight-eu.org/

Tichkiewitch S. \& Brissaud D. (2003), Methods and tools for co-operative and Integrated Design, Dordrecht: Kluwer Academic Publisher.

Terzi S., Bouras A., Dutta D., Garetti M. \& Kiritsis D. (2010), Product lifecycle management - from its history to its new role, International Journal of Product Lifecycle Management, 4(4) 360-389. 
Theret J.P., Zwolinski P. \& Mathieux F. (2011), Integrating CAD, LM and LCA: a new architecture and integration proposal, Proc. Int. Conf. Renewable Energy and Eco-Design in Electrical Engineering - iREED'11, Lille, France, March 23-24.

Ullman, D.G. (1997), The Mechanical Design Process, 2nd Edition, New York: McGraw-Hill.

Vallet F., Millet D., Eynard B., Glatard-Mahut S., Tyl B. \& Bertoluci G. (2013). Using eco-design tools: An overview of experts' practice, Design Studies, 34(1), 345-377

Wijngaards N.J.E., Boonstra H.M. \& Brazier F.M.T. (2003), The role of trust in distributed design, Artificial Intelligence for Engineering Design, Analysis and Manufacturing, 17(3), 253-270

World Commission on Environment Development - WCED (1987), Our Common Future - From one Earth to one World, Oxford: Oxford University Press.

Zhou C.H., Eynard B., \& Roucoules L. (2009) Interoperability between PLM and RoHS Compliance Management based on XML and Smart Client, Journal of Computing and Information Science in Engineering, 9(3). 